ПАВЛОВА П. А., БАКУШКИНА Н. И., СУЛЕЙМАНОвА Е. В., ПАВЛОВА Н. В., ЛАвРОвА М. А., ТУКТАРевА И. В., ... МАКСИМОВ Д. М. АПРОБАЦИЯ МЕТОДИКИ «Bayley Scales of Infant and Toddler Development - Third Edition»

РосСиЙСКИй псИХологИЧЕСКИй ЖУРнАл, 2020, Т. 17, № 4, 49-64. doi: 10.21702/rpj.2020.4.4

ПСИХОЛОГИЯ РАЗВИТИЯ

УдК 159.9.075 doi: $10.21702 /$ rpj.2020.4.4

Оригинальная научная статья

\title{
Апробация методики «Bayley Scales of Infant and Toddler Development - Third Edition»
}

Полина А. Павлова ${ }^{1 *}$, НалежАа И. Бакушкина', Екатерина В. Сулейманова', Належаа В. Павлова', Мария А. Ааврова', Инна В. Туктарева', Амитрий А. Чегодаев', О^ьга А. Аьвова ${ }^{1,2}$, Амитрий М. Максимов

1 Уральский фредеральный университет имени первого Презилента России Б. Н. Ельцина, г. Екатеринбург, Российская ФеАерация

2 Уральский государственный меАицинский университет Министерства зАравоохранения Российской Фелерации, г. Екатеринбург, Российская Федерация

* E-mail: polinaalexpavlova@gmail.com

ORCID ID: https://orcid.org/0000-0003-4263-0484, https://orcid.org/0000-0003-4578-6820, https://orcid.org/0000-0002-1718-1798, https://orcid.org/0000-0002-0577-3171, http://orcid.org/0000-0003-4781-9833, https://orcid.org/0000-0003-1984-517X, https://orcid.org/0000-0001-5123-127X, https://orcid.org/0000-0002-2280-3096, https://orcid.org/0000-0001-8525-2116

\begin{abstract}
Аннотация
Ввеление. В Российской Фелерации (РФ) в настоящее время отсутствует универсальная комп^ексная метолика оценки Аетского развития. В зарубежной практике в качестве подобного инструмента широко используются шкалы Bayleу-ІІІ, разработанные американскими учеными. Значительное количество исследовательских групп отмечает необходимость аАаптации оригинальных Шкал при использовании в новой языковой и социально-культурной среАе. Метолы. Выполнен перевод оригинального руководства Bayley-III на русский язык; впервые проведена апробация метолики в российской популяции путем оценки когнитивного, речевого и моторного развития 163 детей в возрасте 2-11 месяцев; произведено непрямое сравнение полученных средних шкальных бал^ов нервно-психического развития с показателями Аетей из оригинальной американской выборки с применением Т-критерия СтьюАента.

Результаты. Проведена успешная апробация руковолства Baylеу-ІІІ в РФ. Показатели речевого и моторного развития обслеАованных Аетей статистически не отличались от оригинальных американских Аанных (10 бал^ов). По шкале когнитивного развития были получены более высокие показатели (10,7 балмов против 10; $p=0,003)$, олнако степень этого отличия была мало выражена (размер эороректа Cohen's $d=0,25$ ).

ОбсужАение резумьтатов. Показатели нервно-психического развития Аетей из российской популяции фактически полностью соответствовали нормативным Аанным оригинальной Bayley-ІІІ, что открывает возможности применения инструмента в РФ. Несколько более высокие показатели когнитивного развития у обслеАованных российских Аетей в целом не меняют общей картины соответствия оригинальной методике, поскольку размер полученного отличия невелик. Результаты исслеАОвания можно экстраполировать на Аоношенных Аетей европеоилной расы в возрасте 2-11 месяцев, родители которых имели как минимум среднее
\end{abstract}


ПАВЛОВА П. А., БАКУШКИНА Н. И., СУЛЕЙМАНОВА Е. В., ПАВЛОВА Н. В., ЛАВРОВА М. А., ТУКТАРеВА И. В., ... МАКСИМОВ Д. М. АПРОБАЦИЯ МЕТОДИКИ «Bayley Scales of Infant and Toddler Development - Third Edition»

Российский психологический жУРнАл, 2020, Т. 17, № 4, 49-64. doi: 10.21702/rpj.2020.4.4

ПСИХОЛОГИЯ РАЗВИТИЯ

образование и средний уровень Аохола. Аля Широкого использования Bayley-ІІІ необхоли-

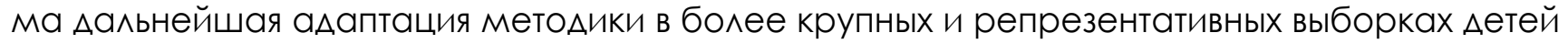
из разных регионов РФ С Аополнительной оценкой социально-эмоционального развития и алаптивного поведения.

\section{КАючевые слова}

шкалы Bayley-III, Бэйли-3, нервно-психическое развитие, млаленцы, апробация, алаптация, оценка развития, комплексное развитие, когнитивная сорера, моторная сорера

\section{Основные положения}

> в рамках изучения зарубежной метолики оценки комплексного развития Аетей ВауІеу-ІІІ выполнен анализ структуры шка^, оригинальной процеАуры стандартизации и опыта алаптации/апробации метолики;

$\checkmark$ проведена апробация русской версии Bayley-III путем оценки нервно-психического развития 163 летей в возрасте от 2 Ао 11 месяцев, проживающих в г. Екатеринбурге и СверАловской области;

> проведено непрямое сравнение полученных данных с оригинальными нормативными показателями Bayley-III;

> показатели по когнитивной, речевой и моторной шкалам продемонстрировали высокий уровень соответствия нормам Bayley-III и могут быть экстраполированы на популяцию Аетей РФ, с учетом ограничений.

\section{Для цитирования}

Павлова, П. А., Бакушкина, Н. И., Сулейманова, Е. В., Павлова, Н. В., Лаврова, М. А., Туктарева, И. В., ... Максимов, Д. М. (2020). Апробация методики «Bayley Scales of Infant and Toddler Development - Third Edition». Российский психологический журнал, 17(4), 49-64. doi: 10.21702/rpj.2020.4.4

Дата получения рукописи: 14.08 .2020 Дата окончания рецензирования: 23.10 .2020 Дата принятия к публикации: 24.10.2020

\section{Введение}

Начальный период развития ребенка уже давно является предметом пристального научного внимания, как со стороны психологов, так и со стороны медицинского сообщества. Этот интерес обусловлен важностью своевременной диагностики отклоняющегося развития в раннем детском возрасте, а также существенной генетической и фенотипической вариабельностью, определяющей нейропсихическое развитие ребенка. Многие из подобных нарушений диагностируются достаточно поздно, на втором, третьем годах жизни, хотя отдельные маркеры атипичного развития можно обнаружить в младенческом возрасте. Также, несмотря на обилие методик, направленных на изучение развития ребенка, в Российской Федерации (РФ) отсутствует «золотой стандарт» оценки комплексного детского развития (Кустова, Таранушенко и Демьянова, 2018).

С учетом вышеизложенного, высокую актуальность приобретает задача поиска и апробации эффективных диагностических инструментов, способных с высокой точностью определять 
ПАВЛОВА П. А., БАКУШКИНА Н. И., СУЛЕЙМАНОвА Е. В., ПАВЛОВА Н. В., ЛАвРОвА М. А., ТУКТАРевА И. В., ... МАКСИМОВ Д. М. АПРОБАЦИЯ МЕТОДИКИ «Bayley Scales of Infant and Toddler Development - Third Edition»

РосСиЙСКИй псИХологИЧЕСКИй ЖУРнАл, 2020, Т. 17, № 4, 49-64. doi: 10.21702/rpj.2020.4.4

ПСИХОЛОГИЯ РАЗВИТИЯ

отклонения развития в течение первых лет жизни. Выявление задержки развития в данный период, когда компенсаторные возможности организма находятся на высоком уровне, потенциально может существенно повысить эффективность коррекционных терапевтических вмешательств.

При этом в мировой практике одним из наиболее изученных диагностических инструментов являются так называемые «Шкалы развития Бэйли» (Bayley Scales of Infant and Toddler Development - Third Edition, далеe - Bayley-III) (Bayley, 2006). Вayley-III широко признается в качестве «золотого стандарта» для оценки комплексного развития детей в возрасте от 16 дней до 3,5 лет (Azari et al., 2017; Ranjitkar et al., 2018; Yue et al., 2019). Методика основана на известных и общепринятых теориях развития (Д. Брунер, Л. С. Выготский, А. Р. Лурия, Ж. Пиаже) и согласуется с результатами исследований в области детского развития, включая нейропсихологические исследования и исследования обработки информации (Aylward, 1988; Colombo \& Cheatham, 2006; Colombo \& Mitchell, 2009), функциональную социально-эмоциональную теорию (Greenspan, DeGangi, \& Wieder, 2001) и теорию адаптивного поведения (Weiss, Oakland, \& Aylward, 2010).

Существенным ограничением для широкого прикладного применения Bayley-III в РФ является отсутствие возрастных нормативных показателей для российской популяции детей. Результаты кросс-культурных исследований показывают необходимость адаптации этой методики с учетом языковых различий и социальных особенностей населения (Azari et al., 2017; Hegde, Rao, Raguram, \& Gangadhar, 2013; Hoskens, Klingels, \& Smits-Engelsman, 2018; Fuiko et al., 2019; Steenis, Verhoeven, Hessen, \& van Baar, 2015; Sun et al., 2019). Использование Bayley-III без предварительной стандартизации может привести к неверной интерпретации полученных результатов, выражающейся в переоценке или, напротив, недооценке уровня развития ребенка.

Несмотря на то, что методика активно используется в мире с 2006 г., в РФ ее прикладная адаптация до сих пор не проведена. Тем не менее, Bayley-III активно применяется в научно-исследовательских целях, а также в клинических исследованиях (№ BN40703). Ввиду обозначенного ограничения, большинство авторов применят данную методику не как диагностическую, а как экспериментальную, при этом используя для статистического анализа преимущественно абсолютные значения сырых баллов (Киселев и др., 2016; Белоусова и Швец, 2019; Бакушкина, Киселев, Львова, Сулейманова и Туктарева, 2018; Киселев, Львова и Бакушкина, 2016). В ограниченном количестве статей встречается использование преобразованных баллов, границы нормы которых выделены на основании данных американской выборки (Заваденко, Медведев и Дегтярева, 2018; Косякова и Беспалова, 2019; Шифман, 2016).

Таким образом, актуальность применения Bayley-III и ограничения для ее полноценного использования в качестве диагностического инструмента диктуют необходимость проведения процедуры апробации и адаптации на российской популяции детей. В качестве первого этапа этой процедуры авторами настоящего исследования были проведены анализ структуры шкал Bayley-III и изучение оригинальной процедуры стандартизации, а также систематизированный анализ опыта адаптации/апробации методики в зарубежных исследованиях. Перед апробацией оценочных шкал на российской выборке был осуществлен перевод методического руководства и бланков Bayley-III на русский язык. В качестве финального этапа было проведено экспериментальное исследование нервно-психического развития 163 детей от 2 до 11 месяцев с помощью адаптированной методики Bayley-III; полученные данные были сопоставлены с оригинальными показателями детей из американской популяции. 
ПАВЛОВА П. А., БАКУШКИНА Н. И., СУЛЕЙМАНОвА Е. В., ПАВЛОВА Н. В., ЛАВРОВА М. А., ТУКТАРевА И. В., ... МАКСИМОВ Д. М. АПРОБАЦИЯ МЕТОДИКИ «Bayley Scales of Infant and Toddler Development - Third Edition»

Российский психологический жУРнАл, 2020, Т. 17, № 4, 49-64. doi: 10.21702/rpj.2020.4.4

ПСИХОЛОГИЯ РАЗВИТИЯ

\section{Структура методики Bayley-III}

В третьем издании методики Bayley используется эффективный дизайн администрирования, который основан на определении стартовых возрастных точек, реверсивном принципе и критериях прекращения тестирования (Bayley, 2006).

Bayley-III включает пять шкал, каждая из которых содержит определенное количество проб: (1) когнитивная - 91 проба; (2) речевая (подразделяется на следующие субшкалы: рецептивная коммуникация - 49 проб, экспрессивная коммуникация - 48 проб); (3) моторная (субшкалы: мелкая моторика - 66 проб, крупная моторика - 72 пробы); (4) шкала социально-эмоционального развития - 35 проб и (5) шкала адаптивного поведения - 241 проба. Оценка по когнитивной, речевой и моторной шкалам осуществляется на основании выполнения проб ребенком (прямое тестирование), которые в совокупности направлены на диагностику нервно-психического развития (НПР) ребенка. Шкалы социально-эмоционального и адаптивного развития используют непрямое тестирование - представлены в виде опросника, заполняемого специалистом на основании ответов родителя об особенностях поведения ребенка в повседневной жизни.

При правильном выполнении пробы ребенком в бланке проставляется один балл, баллы по каждой шкале суммируются. Полученные так называемые «сырые» баллы переводятся в (1) шкальные баллы, определяющие коридор нормативного развития; (2) композитные баллы, используемые для сопоставления и сравнения показателей всех шкал, а также выявления индивидуальных особенностей развития ребенка; (3) процентили, позволяющие оценить частоту встречаемости показателей, полученных ребенком, в популяции, на которой была стандартизована выборка.

\section{Стандартизация методики Bayley-III в США}

Набор участников в рамках оригинальной стандартизации методики Bayley-III был осуществлен в Соединенных Штатах Америки (США) в период с января по октябрь 2004 г. на основе данных переписи 2000 г. (Bayley, 2006). Выборка была стратифицирована по демографическим показателям, включающим возраст, пол, этническую принадлежность, географический регион, уровень образования родителей или другого лица, осуществляющего основной уход за ребенком. Выборка составила 17 возрастных групп с буквенными обозначениями от A до Q, включающих 1700 детей в возрасте от 16 дней до 43 месяцев 15 дней. В каждой группе дети были уравнены по полу, большая часть участников была европеоидной расы, их родители имели средний или выше среднего уровни образования и дохода.

В связи с целями и задачами последующего применения методики, а именно необходимостью оценки соответствия развития ребенка возрастным нормам, основной объем выборки составили «типично развивающиеся» дети. В данную категорию включались дети, рожденные в сроке гестации 37-42 недели, без существенной неврологической и соматической патологии в анамнезе, не получавшие лечение в связи с наличием психических, физических или поведенческих расстройств, а также не имевшие следующих диагнозов: синдрома дефицита внимания и гиперактивности (СДВГ); хромосомных аномалий; заболеваний, обусловленных пренатальной экспозицией токсических веществ (включая фетальный алкогольный синдром); врожденных пороков центральной нервной системы (ЦНС); генетических или врожденных заболеваний; умственной отсталости; внутрижелудочкового кровоизлияния; патологии дыхательной системы; тяжелых расстройств привязанности; тяжелых сенсорных нарушений; малого веса при рождении; недоношенности. 
ПАВЛОВА П. А., БАКУШКИНА Н. И., СУЛЕЙМАНОвА Е. В., ПАВЛОВА Н. В., ЛАвРОвА М. А., ТУКТАРевА И. В., ... МАКСИМОВ Д. М. АПРОБАЦИЯ МЕТОДИКИ «Bayley Scales of Infant and Toddler Development - Third Edition»

РосСиЙСКИй псИХологИЧЕСКИй ЖУРнАл, 2020, Т. 17, № 4, 49-64. doi: 10.21702/rpj.2020.4.4

ПСИХОЛОГИЯ РАЗВИТИЯ

Дети исключались из основной исследовательской выборки, если они получали помощь в рамках программы «Early Childhood Intervention», имели факторы риска, влияющие на развитие ЦНС, а также если они принимали лекарственные препараты, которые могли повлиять на переносимость физических и интеллектуальных нагрузок, на момент тестирования проходили стационарное лечение, имели нарушения слуха или зрения, их родители не являлись носителями английского языка.

Приблизительно 10 \% выборки составляли дети, имевшие клинический диагноз (синдром Дауна, церебральный паралич, аутизм, синдром Аспергера, синдром Ретта, когнитивную эпилептиформную дезинтеграцию, недоношенность, фетальный алкогольный синдром, специфические расстройства развития речи, асфиксию, гипотрофию и др.). Эта категория детей была специально добавлена в экспериментальную выборку с целью повышения ее репрезентативности.

\section{Aдаптация/апробация методики Bayley-III}

Ввиду своей диагностической значимости Bayley-III получила широкое распространение в мире. Примеры зарубежных исследований, в которых была проведена процедура адаптации или апробации методики, представлены в таблице 1.

Таблица 1
Публикации по алаптации/апробации методики Bayley-III

\begin{tabular}{|c|c|c|}
\hline$\frac{\text { Авторы, }}{\text { страна, гоА }}$ & Характеристика выборки & Описание процедуры и результатов \\
\hline $\begin{array}{l}\text { Hua et al., } \\
\text { Китай, } 2019\end{array}$ & 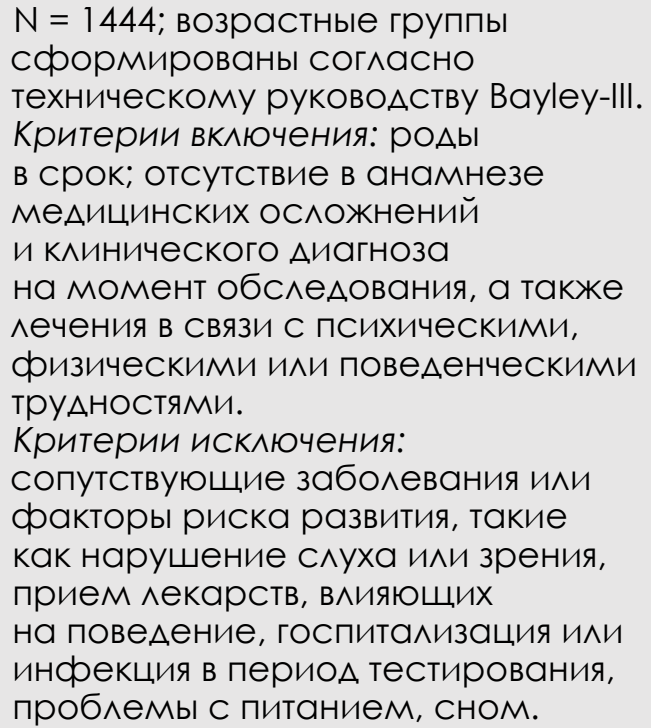 & $\begin{array}{l}\text { Были осуществлены прямой и обратный } \\
\text { перевол, а также культурная } \\
\text { алаптация. ПровоАилась Аиагностика } \\
\text { детей только по когнитивной шкале. } \\
\text { Оценка тест-ретестовой належности, } \\
\text { взаимосвязи и належности критериев } \\
\text { на соответствие психометрическим } \\
\text { критериям Вауеу-ІІІ на случайно взятых } \\
\text { из всей выборки 5-10\% Аетей. } \\
\text { Выводы: когнитивная шкала Вауlеу- } \\
\text { ІІІ может быть использована Аля } \\
\text { оценки развития, а также Аля учета } \\
\text { половых различий при использовании } \\
\text { на китайской выборке. }\end{array}$ \\
\hline
\end{tabular}


ПАВЛОВА П. А., БАКУШКИНА Н. И., СУЛЕЙМАНОвА Е. В., ПАВЛОВА Н. В., ЛАВРОВА М. А., ТУКТАРевА И. В., ... МАКСИМОВ Д. М. АПРОБАЦИЯ МЕТОДИКИ «Bayley Scales of Infant and Toddler Development - Third Edition»

Российский психологичЕский жУРнАл, 2020, Т. 17, № 4, 49-64. doi: 10.21702/rpj.2020.4.4

ПСИХОЛОГИЯ РАЗВИТИЯ

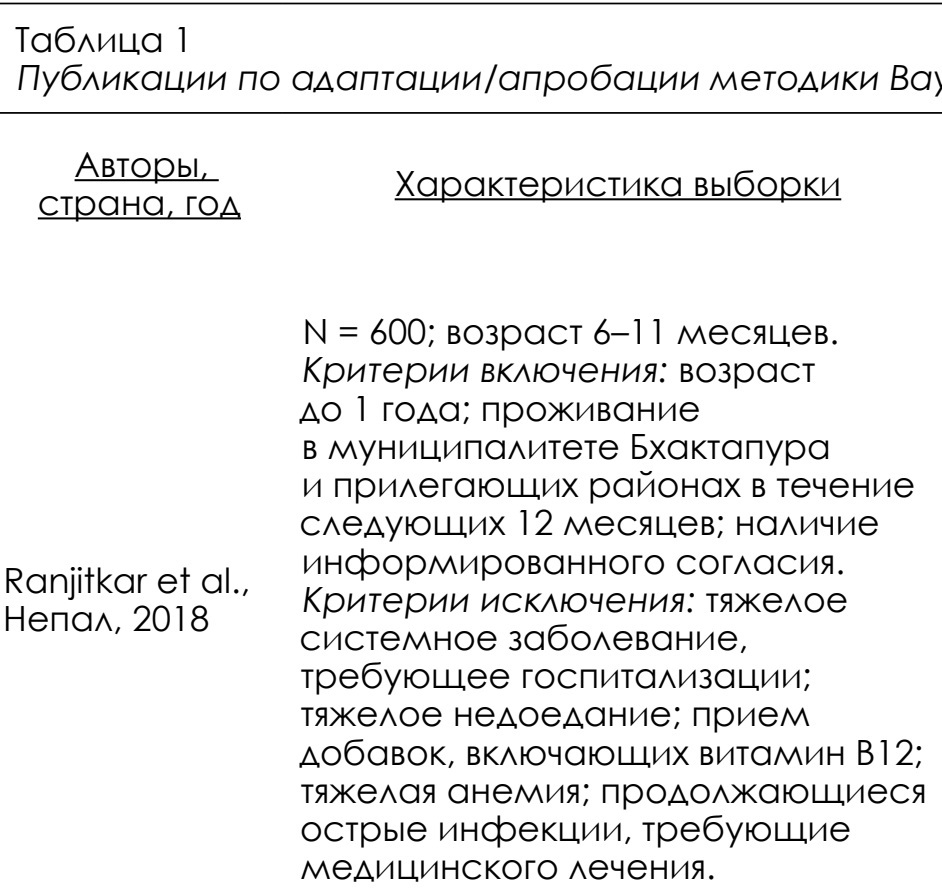

Krogh et al.,

Аания, 2012

4, 7, 10 и 13 месяцев.

Критерии искАючения:

неАоношенность; наличие

оризических/Умственных

расстройств.

\section{Описание процедуры и результатов}

Осуществлены прямой и обратный перевол метолики, алаптация метолики с учетом культурных особенностей. Выборка вкАюча^а 10\% неАОношенных Аетей.

ВывоАы: показатели по когнитивной и моторным шкалам сопоставимы с американскими нормами. Балмы по языковым Шкалам были значимо ниже, чем в американской выборке и требуют особого внимания при интерпретации. В целом метолику Bayley-III можно использовать на непальских Аетях в возрасте 6-11 месяцев. Культурная алаптация и стандартизация - преАпосылКИ А^я более Аостоверной и належной оценки С пОМОЩьЮ АанНОЙ МеТОАИКИ.

Осуществлен прямой перевоА метоАики.

55,1 \% родителей в Аатской выборке имели 16 и более лет обучения. При стандартизации на американской выборке этот процент состави^ 27,6\%. Выводы: получены значимые различия межАу Аатскими и американскими нормами по всем Шка^ам. В частности, в Аании более низкие показатели по рецептивной шкале во всех возрастах. На неамериканских выборках применять Bayley-III следует с осторожностью.

Алаптация не проводи^ась, использовались оригинальный вариант и американские нормы Аля оценки развития австралийских Аетей. ВывоАы: у австралийских Аетей получены более высокие результаты по всем шкалам, кроме моторики. Применение американских норм может привести к неАооценке Аегких

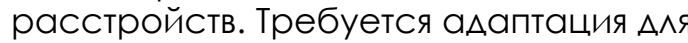
^окальной выборки. 
ПАВЛОВА П. А., БАКУШКИНА Н. И., СУЛЕЙМАНОвА Е. В., ПАВЛОВА Н. В., ЛАвРОвА М. А., ТУКТАРевА И. В., ... МАКСИМОВ Д. М. АПРОБАЦИЯ МЕТОДИКИ «Bayley Scales of Infant and Toddler Development - Third Edition»

РосСиЙСКИй псИХологИЧЕСКИй ЖУРнАл, 2020, Т. 17, № 4, 49-64. doi: 10.21702/rpj.2020.4.4

ПСИХОЛОГИЯ РАЗВИТИЯ

Таблица 1
Публикации по алаптации/апробации методики Bayley-III

Публикации по алаптации/апробации метолики вауіеу-III

Авторы, страна, гоА

Характеристика выборки

Описание процедуры и результатов

$\mathrm{N}=403$; возраст от 1 Ао 42 месяцев (все возрастные группы ИСХОАНОЙ МетОАИКИ A-Q). Минима^ьное количество Аетей $(\mathrm{N}=10)$ в возрастной

Azari et al., Иран, 2017 группе Е. Максимальное количество $(\mathrm{N}=38)$ - в возрастной группе D.

Критерии вКАючения: возраст от 1 Ао 42 месяцев; нормальное развитие и отсутствие какихАибо явных нарушений развития; в^аление персиАским языком.

Осуществлены прямой и обратный перево $А$ метолики, а также алаптация метоАики с учетом культурных особенностей.

ВывоАы: шка^а Bayley-III яв^яется ва^ИАНЫМ И наАежным ИнстрУментом Аля оценки развития Аетей, говорящих на персилском языке.

$N=178$ (недоношенные),

$\mathrm{N}=62$ (рожАенные в срок).

АонгитюАное исслеАование: 6 ,

12, 18 и 24 месяца (по скорректированному возрасту $А \wedge я$ неАОношенных).

Критерии вкАючения (Аоношенные): масса тела при рожАении более 2500 г; срок гестации 38-42 нелель; отсутствие серьезных пренатальных и перината^ьных ос^ожнений. Критерии вкАючения (неАоношенные): мaсcа тела при рожлении менее 1500 г;

Yu et al.,

Тайвань, 2013 гестационный возраст менее 37 недель; вступление в исслеАование в течение 7 Аней С момента рожАения; ребенок Из ОАНОПАОАНОЙ беременностИ ИАи первый ребенок из Многоп^оАНой; отсутствие врожАенных аномалий или тяжелых неонатальных заболеваний.

Аополнительные критерии Аля всех участников: матери старше 18 ^ет, читающие и говорящие на китайском языке; отсутствие в анамнезе АИагнозов алкоголизм и/или наркомания; родители, состоящие в браке на момент рожАения ребенка.

Kроме Bayley-III также проведена оценка по второй версии методики, вслеАствие чего проИзвеАено сравнение результатов по обеим метоАИкам И САеАан ВывоА О ВОЗМОЖНОСТИ ИСПОАЬЗОВанИЯ КаЖАОЙ Из Них.

Выводы: методика Bayley-III является наАежным Инструментом А^я Оценки развития АОношенных И неАОношенных

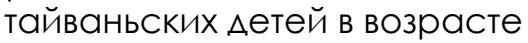
6-24 месяцев. 
ПАВЛОВА П. А., БАКУШКИНА Н. И., СУЛЕЙМАНОвА Е. В., ПАВЛОВА Н. В., ЛАвРОвА М. А., ТУКТАРевА И. В., ... МАКСИМОВ Д. М. АПРОБАЦИЯ МЕТОДИКИ «Bayley Scales of Infant and Toddler Development - Third Edition»

РосСиЙСКИй псИХологИЧЕСКИй ЖУРнАл, 2020, Т. 17, № 4, 49-64. doi: 10.21702/rpj.2020.4.4

ПСИХОЛОГИЯ РАЗВИТИЯ

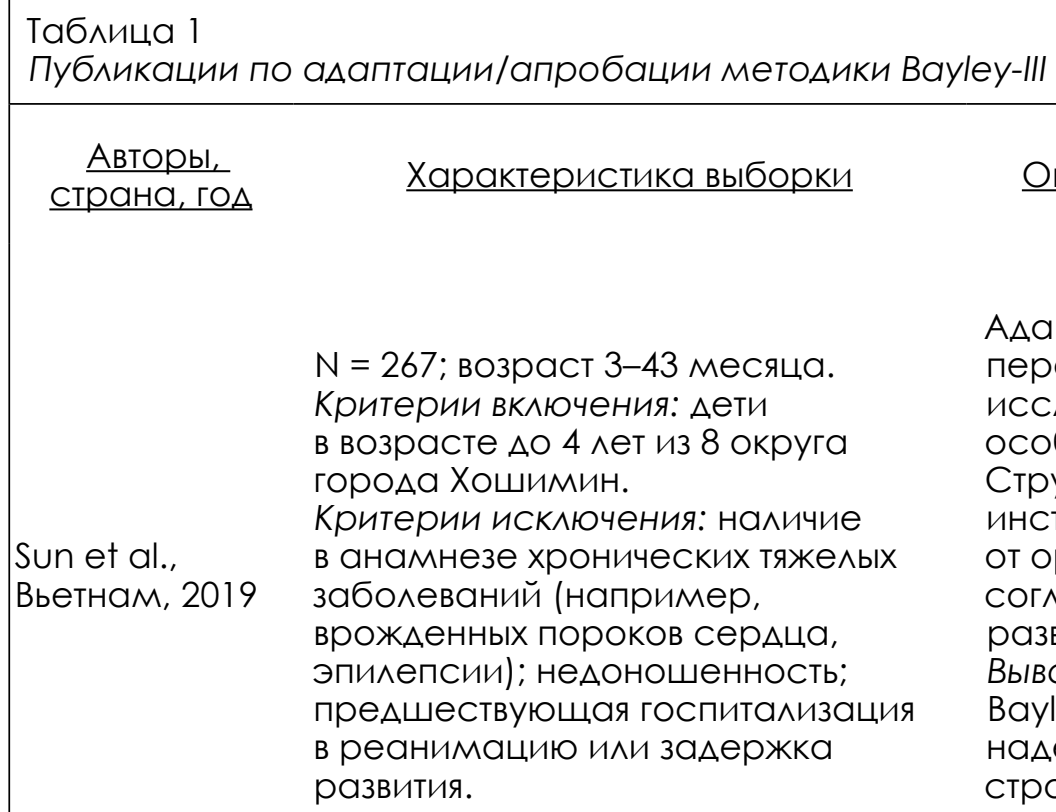

Sun et al., вьетнам, 2019

$\mathrm{N}=267$; возраст 3-43 месяца. Критерии вкАючения: Аети в возрасте $А$ 4 ^ет из 8 округа города Хошимин. Критерии искАючения: наличие в анамнезе хронических тяжелых заболеваний (например, врожАенных пороков серАца, эпилепсии); неАОношенность; преАшествующая госпитализация в реанимацию или залержка развития.

ААаптация путем прямого и обратного перевода, модификации пилотного ИсСАеАОвания согАасно КУАьтурным особенностям.

Структура алаптированного инструмента отличается от оригинальной, оАнако изменения согАасуются с теориями раннего развития.

Выводы: алаптированная версия Bayley-III обладает хорошей належностью, а также отвечает строгим критериям инвариантности Аля гендерных и возрастных групп.

Проведение адаптации, приближенной к оригинальной процедуре (включая прямой и обратный перевод, культурную адаптацию, анализ всех возрастов аналогично оригинальной методике, а также включение 10 \% детей с отклонениями в развитии), из всех представленных исследований было осуществлено только в одном случаe (Steenis et al., 2015). В трех исследованиях методика Bayley-III была проведена во всех возрастных диапазонах в соответствии с оригинальной методикой (Azari et al., 2017; Hua et al., 2019; Steenis et al., 2015); прямой и обратный перевод были произведены в четырех случаях (Azari et al., 2017; Hua et al., 2019; Steenis et al., 2015; Sun et al., 2019); два исследования использовали лонгитюдный дизайн (Krogh, Væver, Harder, \& Køрре, 2012; Yu et al., 2013); в одном из исследований максимальное число детей в возрастных группах составило 38 испытуемых (Azari et al., 2017). Включение 10\% детей с клиническими диагнозами было использовано только в одном исследовании (Steenis et al., 2015), в другой работе в выборку были включены $10 \%$ детей с недоношенностью (Hua et al., 2019).

В значительной части исследований, посвященных адаптации или апробации Bayley-III, у обследованных детей были выявлены отличия от американских норм по всем или по большему количеству шкал (Chinta, Walker, Halliday, Loughran-Fowlds, \& Badawi, 2014; Krogh et al., 2012; Steenis et al., 2015). С другой стороны, многие авторы продемонстрировали возможность успешного применения американских норм на локальной выборке без предварительной культурной адаптации (Ballot et al., 2017; Yu et al., 2013). В целом большая часть исследований указывает на надежность инструмента после адаптации методики (Azari et al., 2017; Hanlon et al., 2016; Hua et al., 2019; Ranjitkar et al., 2018; Sun et al., 2019). Таким образом, большинство вариантов адаптации методики являются неполными и, несмотря на выводы о возможности применения разработанных вариантов, результаты диагностики следует интерпретировать с осторожностью. 
ПАВЛОВА П. А., БАКУШКИНА Н. И., СУЛЕЙМАНОвА Е. В., ПАВЛОВА Н. В., ЛАВРОВА М. А., ТУКТАРевА И. В., ... МАКСИМОВ Д. М. АПРОБАЦИЯ МЕТОДИКИ «Bayley Scales of Infant and Toddler Development - Third Edition»

Российский психологический жУРнАл, 2020, Т. 17, № 4, 49-64. doi: 10.21702/rpj.2020.4.4

ПСИХОЛОГИЯ РАЗВИТИЯ

\section{Методы}

Сбор данных был проведен в рамках проекта «Лонгитюдное исследование нейрокогнитивного развития детей», осуществленного на базе Лаборатории мозга и нейрокогнитивного развития департамента психологии ФГАОУ ВПО «Уральский федеральный университет имени первого Президента России Б. Н. Ельцина» (УрФУ). Набор детей осуществлялся с использованием ресурсов департамента психологии УрФУ, кафедры неврологии детского возраста и неонатологии Уральского государственного медицинского университета, а также Екатеринбургского клинического перинатального центра (Детская городская больница № 10). Проект был одобрен этическим комитетом при ГБОУ ВПО «Уральская государственная медицинская академия» Министерства здравоохранения и социального развития РФ. Законным представителям участников детского возраста была предоставлена информация о целях и методах проекта, объяснен принцип сохранения анонимности личных данных. Перед включением в проект осуществлялась процедура оформления добровольного информированного согласия.

Обследование осуществлялось по 3 шкалам (со всеми соответствующими субшкалами): (1) когнитивной, (2) речевой, (3) моторной. Показатели шкал, заполняемых специалистом на основании ответов родителя/опекуна (социально-эмоциональная сфера и сфера адаптивного развития) не были использованы по причине более низкой надежности. Исследование с применением методики проводилось научными сотрудниками лаборатории, прошедшими сертифицированное обучение использованию Bayley-III в качестве психодиагностического инструмента. Проведение исследования осуществлялось в специально оборудованном помещении с параллельной видеорегистрацией процесса с целью последующего дополнительного анализа поведения ребенка и родителя.

Психодиагностическая методика Bayley-III, использованная в исследовании, была официально закуплена в издательстве (Англия). Диагностический материал и содержательный аспект проводимых проб соответствовал российской социально-культурной среде. Ввиду этого использовался оригинальный стимульный материал в соответствии с правилами администрирования методики Bayley-III и применением переведенных на русский язык бланков.

Прямой перевод методики и бланков Bayley-III был осуществлен с сохранением контекстуального значения. Сложности в адаптации методики прежде всего были связаны с различиями грамматики английского и русского языков. Например, в пробе 34 субшкалы рецептивной коммуникации и в пробе 34 субшкалы экспрессивной коммуникации в оригинальной версии методики предполагается оценка понимания и использования ребенком настоящего длительного времени (present continuous), не имеющего прямого аналога в русской речи. В русском языке настоящее время предпочтительнее при описании статических ситуаций, событий, происходящих в данный момент (что используется при проведении диагностики). В связи с этим при переводе данные пробы были модифицированы следующим образом: в первом случае анализируется понимание, во втором случае-употребление ребенком глаголов в настоящем времени. Данные пробы предназначены для детей старше 1,5 лет.

Для набора участников исследования были использованы следующие критерии включения: доношенные дети (срок гестации 37 недель и более по критериям ВО3) от 2 месяцев 16 дней до 10 месяцев 30 дней, антропометрические показатели которых при рождении находились в рамках физиологической нормы.

Для повышения репрезентативности и соответствия оригинальной методике в выборку были дополнительно включены $10 \%$ детей с отягощенным семейным анамнезом по СДВГ 
ПАВЛОВА П. А., БАКУШКИНА Н. И., СУЛЕЙМАНОвА Е. В., ПАВЛОВА Н. В., ЛАвРОвА М. А., ТУКТАРевА И. В., ... МАКСИМОВ Д. М. АПРОБАЦИЯ МЕТОДИКИ «Bayley Scales of Infant and Toddler Development - Third Edition»

РосСиЙСКИй псИХологИЧЕСКИй ЖУРнАл, 2020, Т. 17, № 4, 49-64. doi: 10.21702/rpj.2020.4.4

ПСИХОЛОГИЯ РАЗВИТИЯ

и расстройствам аутистического спектра (РАC), а также с клиническими диагнозами - ишемическим инсультом и недоношенностью.

Критерии включения в проект учитывали педиатрические нормы, соответствующие рекомендациям ВО3, с целью сопоставимости результатов исследования с данными методики (Bayley, 2006; Володин, 2009).

Набор детей проводился при участии врачей-педиатров, неврологов, неонатологов из лечебно-профилактических учреждений г. Екатеринбурга. Первичная документация исследования представляла собой анкету, в которой заполнялись антропометрические и клинические показатели детей при рождении, данные анамнеза, информация о наличии РАС и СДВГ.

Показатели полученной выборки детей по основным социально-экономическим и демографическим характеристикам семьи были в целом сопоставимы с американскими данными (Bayley, 2006; Byers-Heinlein \& Lew-Williams, 2013; Rao, Hammen, \& Poland, 2009; Savostyanov et al., 2018). Тем не менее, настоящая выборка имела определенные отличия от популяции, на которой была проведена исходная апробация методики: родители детей преимущественно относились к категории образованного городского населения г. Екатеринбурга и Свердловской области, в то время как оригинальная методика охватывала представителей всех социальных слоев и регионов США. Также в американской выборке среди детей с неврологической патологией был представлен больший спектр заболеваний, в том числе было больше тяжелых расстройств.

В целом полученная выборка состояла из 163 детей 2-11 месяцев европеоидной расы, проживавших преимущественно в г. Екатеринбурге, родители которых имели среднее или высшее образование, средний или высокий уровень дохода.

Статистическая обработка данных осуществлялась с помощью программного обеспечения Gretl 2019d. Для непрямого сравнения полученных средних шкальных баллов с американскими нормативными значениями (которые составляли 10 ( \pm 3$)$ баллов для всех шкал во всех возрастных группах) был использован t-критерий Стьюдента. За показатель статистической значимости отличий было принято значение $\mathrm{p}<0,05$. При вычислении степени различия шкальных баллов использовался показатель размера эффекта (Cohen, 1988).

\section{Результаты}

Полученная выборка составила 163 младенцев в возрастном диапазоне от 2 месяцев 24 дней до 10 месяцев 29 дней (64\% мальчиков), включая около $10 \%$ детей с отягощенным семейным анамнезом по РАС и СДВГ или клиническим диагнозом. Антропометрические и клинические показатели обследованных детей на момент рождения представлены в таблице 2. Параметры типично развивающихся детей при рождении соответствовали критериям доношенности ВОЗ. Дети с патологией имели один либо клинический диагноз (ишемический инсульт, $\mathrm{n}=4$; недоношенность, $\mathrm{n}=5$ ), либо отягощенный семейный анамнез (риск РАС, $\mathrm{n}=4$; риск СДВГ, $\mathrm{n}=2$ ). По индексу Апгар для детей с клиническим диагнозом и отягощенным семейным анамнезом значения по всем характеристикам были выше на 1 балл в сравнении с детьми «нормы».

Показатели НПР детей РФ в целом соответствовали оригинальным данным по трем основным шкалам: когнитивной, речевой и моторной (табл. 3). При этом средний показатель когнитивного развития российских детей был немного выше оригинальных американских нормативов в соответствующем возрастном диапазоне (10,7 баллов против 10), что было убедительно подтверждено статистически $(p=0,003)$. Однако по размеру эффекта это различие было слабо выраженным (0,7 балла; Cohen's $d=0,25)$. Статистически значимые различия 
ПАВЛОВА П. А., БАКУШКИНА Н. И., СУЛЕЙМАНОВА Е. В., ПАВЛОВА Н. В., ЛАВРОВА М. А., ТУКТАРеВА И. В., ... МАКСИМОВ Д. М. АПРОБАЦИЯ МЕТОДИКИ «Bayley Scales of Infant and Toddler Development - Third Edition»

Российский психологичЕский жУРнАл, 2020, Т. 17, № 4, 49-64. doi: 10.21702/rpj.2020.4.4

ПСИХОЛОГИЯ РАЗВИТИЯ

по субшкалам рецептивной и экспрессивной коммуникации, мелкой и крупной моторики отсутствовали (табл. 3).

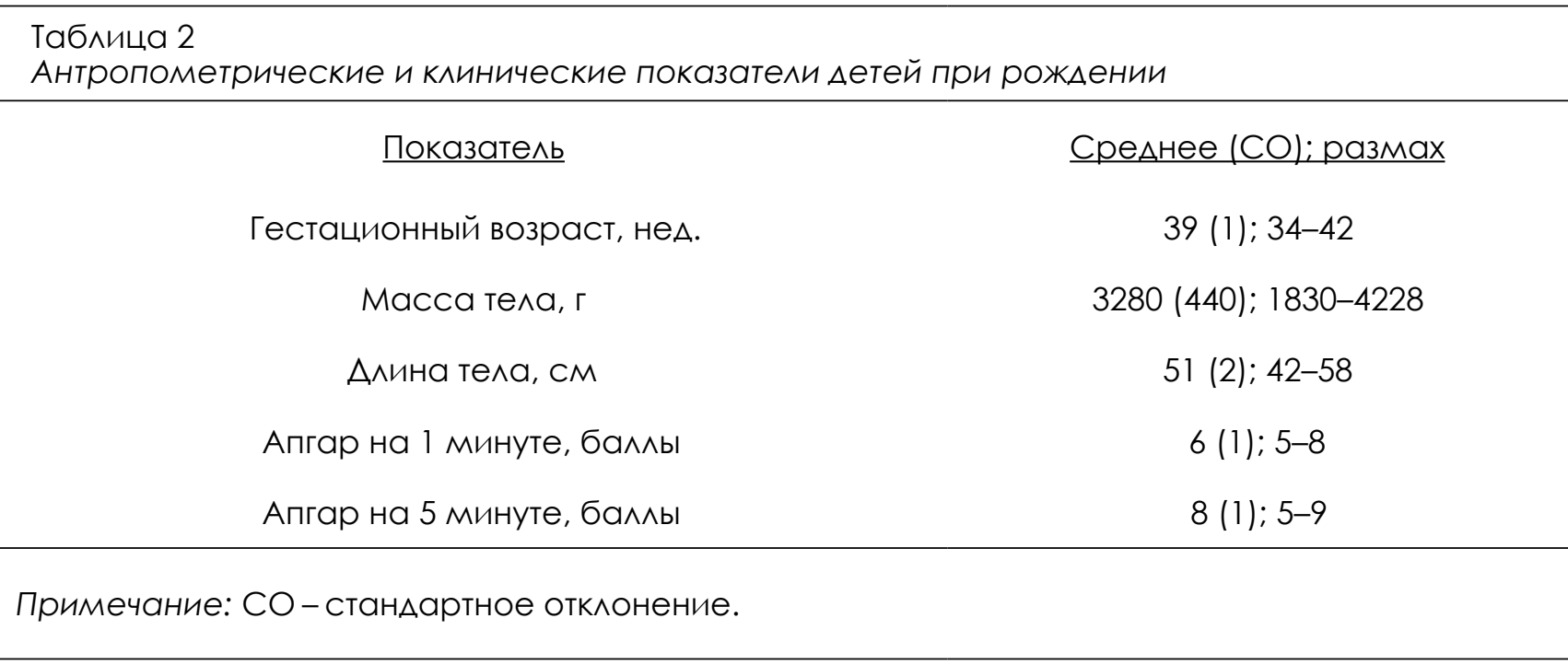

\begin{tabular}{|c|c|c|c|}
\hline \multicolumn{4}{|c|}{$\begin{array}{l}\text { Таблица } 3 \\
\text { Сравнение шкамьных бамлов Bayley-ІІІ российской и американской выборок }\end{array}$} \\
\hline Шкa^a & $\begin{array}{l}\text { Шкальные баллы } \\
\frac{\text { исслеАования (1) }}{(n=163)}\end{array}$ & $\begin{array}{l}\frac{\text { Шкальные балАы }}{\text { оригинальные (1) }} \\
\frac{(n=600)}{1}\end{array}$ & $p(2)$ \\
\hline Когнитивная & $\begin{array}{c}10,7(2,57) \\
\Delta И 95 \%[10,3-11,1]\end{array}$ & $10(3)$ & 0,003 \\
\hline $\begin{array}{l}\text { Рецептивная } \\
\text { коммуникация }\end{array}$ & $\begin{array}{c}9,67(2,24) \\
\Delta И 95 \%[9,32-10]\end{array}$ & $10(3)$ & 0,1 \\
\hline $\begin{array}{l}\text { Экспрессивная } \\
\text { коммуникация }\end{array}$ & $\begin{array}{c}10,2(1,95) \\
\Delta И 95 \%[9,85-10,5]\end{array}$ & $10(3)$ & 0,3 \\
\hline Мелкая моторика & $\begin{array}{c}10(2,24) \\
\Delta И 95 \%[9,69-10,4]\end{array}$ & $10(3)$ & 1 \\
\hline Крупная моторика & $\begin{array}{c}9,98(2,57) \\
\Delta И 95 \%[9,58-10,4]\end{array}$ & $10(3)$ & 0,9 \\
\hline
\end{tabular}


ПАВЛОВА П. А., БАКУШКИНА Н. И., СУЛЕЙМАНОвА Е. В., ПАВЛОВА Н. В., ЛАвРОвА М. А., ТУКТАРевА И. В., ... МАКСИМОВ Д. М. АПРОБАЦИЯ МЕТОДИКИ «Bayley Scales of Infant and Toddler Development - Third Edition»

РосСиЙСКИй псИХологИЧЕСКИй ЖУРнАл, 2020, Т. 17, № 4, 49-64. doi: 10.21702/rpj.2020.4.4

ПСИХОЛОГИЯ РАЗВИТИЯ

\section{Обсуждение результатов}

В рамках экспериментального исследования проведена апробация шкал когнитивного, речевого и моторного развития методики Bayley-III на выборке детей первого года жизни. Апробация включала перевод оригинального руководства и бланков методики, анализ использования оценочных шкал в других популяциях и анализ структуры оригинальной стандартизации.

Непрямое сравнение средних шкальных баллов российских детей с оригинальными американскими данными, на которых методика Bayley-III была изначально стандартизирована, продемонстрировало отсутствие значимых различий по субшкалам экспрессивной и рецептивной речи, крупной и мелкой моторики в возрастном диапазоне от 2 месяцев 16 дней до 10 месяцев 30 дней. Этот результат, с одной стороны, подтверждает качество перевода и адаптации оригинальной методики, а с другой говорит о вероятном соответствии нормативных коридоров НПР у российских и американских детей. У российских детей были получены более высокие (на 0,7 балла) показатели по шкале когнитивного развития, что могло быть следствием локальных особенностей выборки исследования, в частности, смещения социально-демографических характеристик в сторону более образованных городских семей, а также отличий в особенностях детей с неврологической патологией. Однако в целом прикладная значимость подобного различия (размер эффекта) была незначительной. С учетом выявленных закономерностей увеличение объема и репрезентативности выборки, как, например, в исследовании китайских авторов (Hua et al., 2019), наверняка приведет к полному статистическому соответствию оригинальным американским данным по когнитивной шкале.

Если обратиться к рассмотренным ранее зарубежным исследованиям, которые проводили процедуру адаптации/апробации на других этнических выборках, стоить отметить, что результаты, полученные на российской выборке детей, могут быть сопоставимы лишь с некоторыми из них, в том числе только по отдельным шкалам. Так, например, Ranjitkar et al. (2018) при апробации Bayley-III в Непале, так же как Chinta et al. (2014) в Австралии, получили результаты, которые сопоставимы с результатами российской выборки только по шкалам мелкой и крупной моторики. Исследование, проведенное в Дании (Krogh et al., 2012), показало, что результаты отличаются от полученных на российской выборке по субшкалам рецептивной и экспрессивной коммуникации, крупной моторики (более низкие), а также по субшкале мелкой моторики (более высокие) в возрасте до 11 месяцев; результаты по когнитивной шкале могут быть сопоставимы.

С другой стороны, в отличие от российских данных, результаты, полученные на выборке голландских детей, значимо различались по всем шкалам (Steenis et al., 2015). Однако необходимо отметить, что это единственное исследование, включившее в выборку $10 \%$ детей с клиническими диагнозами и рисками задержки развития.

Следует обратить внимание, что в каждом из упомянутых исследований были применены различные процедуры сравнения с оригинальными данными Bayley-III, что также могло повлиять на интерпретацию результатов. Кроме того, отличались: сама процедура апробации/ адаптации методики (выполнение прямого и обратного перевода, культурной адаптации, трансформация стимульного материала и др.), возраст обследованных детей, социально-демографические параметры участников исследования и др. Таким образом, делать какие-либо выводы о сопоставимости результатов, полученных на российской выборке, с данными других этнических исследований достаточно сложно. 
ПАВЛОВА П. А., БАКУШКИНА Н. И., СУЛЕЙМАНОвА Е. В., ПАВЛОВА Н. В., ЛАВРОВА М. А., ТУКТАРевА И. В., ... МАКСИМОВ Д. М. АПРОБАЦИЯ МЕТОДИКИ «Bayley Scales of Infant and Toddler Development - Third Edition»

Российский психологический жУРнАл, 2020, Т. 17, № 4, 49-64. doi: 10.21702/rpj.2020.4.4

ПСИХОЛОГИЯ РАЗВИТИЯ

В целом полученные показатели нормального НПР на российской выборке продемонстрировали почти полное соответствие с оригинальными данными, что говорит о возможности применения оценочных шкал и косвенно подтверждает валидность методики даже при переносе в другую языковую и социально-культурную среду. Этот предварительный результат позволяет с оптимизмом смотреть на дальнейшее использование шкал Bayley-III не только как экспериментальной методики, но и как клинического диагностического инструмента оценки НПР. Тем не менее, с учетом ограничений настоящей выборки полученные результаты можно надежно экстраполировать только на популяцию детей в возрасте от 2 до 11 месяцев из преимущественно социально благополучных образованных городских семей. Кроме того, поскольку компоненты непрямой диагностики (социально-эмоциональная шкала и шкала адаптивного поведения) в настоящем исследовании были исключены из анализа, применять полученные результаты можно только в контексте оценки НПР. В целом для окончательного подтверждения психометрической валидности методики необходимо проведение крупного многоцентрового исследования, выборка которого учитывала бы все основные социально-демографические особенности населения РФ и пропорционально представляла различные регионы с учетом баланса сельского и городского населения.

\section{Литература}

Бакушкина, Н. И., Киселев, С. Ю., Львова, О. А., Сулейманова, Е. В. и Туктарева, И. В. (2018). Использование шкал Бейли (Bayley-III) для оценки нейрокогнитивного развития детей в норме и при патологии. Теоретическая и экспериментальная психология, 11(1), 85-94.

Белоусова, М. В. и Швец, Е. В. (2019). Влияние информационных устройств и факторов социального окружения на развитие речи детей раннего возраста. Вестник современной клинической медицины, 12(3), 15-20. doi: 10.20969/VSKM.2019.12(3).15-20

Володин, Н. Н. (ред.). (2009). Неонатология: национальное руководство. Москва: ГЭОТАР-Медиа.

Заваденко, А. Н., Медведев, М. И. и Дегтярева, М. Г. (2018). Оценка нервно-психического развития детей различного гестационного возраста с неонатальными судорогами. Журнал неврологии и психиатрии им. С. С. Корсакова, 118(11), 35-42. doi: 10.17116/jnevro201811811135

Киселев, С. Ю., Львова, О. А. и Бакушкина, Н. И. (2016). Комплексный подход в диагностике нейрокогнитивных функций у детей, имеющих риск развития расстройств аутистического спектра. Известия Уральского федерального университета. Серия 1: Проблемы образования, науки и культуры, 147(1), 113-121.

Киселев, С. Ю., Львова, О. А., Глига, Т., Бакушкина, Н. И., Сулейманова, Е. В., Гришина, К. И., ... Мартиросян, С. В. (2016). Оценка развития нейрокогнитивных функций у недоношенных детей первого года жизни с помощью шкалы Бейли. Журнал неврологии и психиатрии им. С. С. Корсакова, 116(4-2), 62-67. doi: 10.17116/jnevro20161163262-67

Косякова, О. В. и Беспалова, О. Н. (2019). Профилактика и терапия угрожающих преждевременных родов при многоплодии. Журнал акушерства и женских болезней, 68(4), 55-70. doi: $10.17816 / J O W D 68455-70$

Кустова, Т. В., Таранушенко, Т. Е. и Демьянова, И. М. (2018). Оценка психомоторного развития ребенка раннего возраста: что должен знать врач-педиатр. Медицинский совет, 11, 104-109. doi: 10.21518/2079-701Х-2018-11-104-109

Шифман, Б. (2016). Влияние дополнительного приема йода во время беременности на раннее развитие нервной системы ребенка, клинические результаты: итоги 
ПАВЛОВА П. А., БАКУШКИНА Н. И., СУЛЕЙМАНОвА Е. В., ПАВЛОВА Н. В., ЛАвРОвА М. А., ТУКТАРевА И. В., ... МАКСИМОВ Д. М. АПРОБАЦИЯ МЕТОДИКИ «Bayley Scales of Infant and Toddler Development - Third Edition»

РосСийский психологИческий жУРнАл, 2020, Т. 17, № 4, 49-64. doi: 10.21702/rpj.2020.4.4

ПСИХОЛОГИЯ РАЗВИТИЯ

прерванного рандомизированного плацебо-контролируемого исследования. Интернетжурнал «Актуальная эндокринология». Доступ 22 октября 2020, источник http:// actendocrinology.ru/archives/3878

Aylward, G. P. (1988). Infant and early childhood assessment. In M. G. Tramontana, S. R. Hooper (Eds.), Assessment issues in child neuropsychology. Critical issues in neuropsychology (pp. 225-248). Boston, MA: Springer. doi: 10.1007/978-1-4757-9301-7 9

Azari, N., Soleimani, F., Vameghi, R., Sajedi, F., Shahshahani, S., Karimi, H., ... Gharib, M. (2017). A psychometric study of the Bayley Scales of Infant and Toddler Development in Persian language children. Iranian Journal of Child Neurology, 11(1), 50-56. doi: 10.22037/ijcn.v111i1.12056

Ballot, D. E., Ramdin, T., Rakotsoane, D., Agaba, F., Davies, V. A., Chirwa, T., \& Cooper, P. A. (2017). Use of the Bayley Scales of Infant and Toddler Development, third edition, to assess developmental outcome in infants and young children in an urban setting in South Africa. International Scholarly Research Notices, 2017, 1-5.

Bayley, N. (2006). Bayley Scales of Infant and Toddler Development (3rd ed.). San Antonio, TX: Harcourt Assessment.

Byers-Heinlein, K., \& Lew-Williams, C. (2013). Bilingualism in the early years: What the science says. LEARNing Landscapes, 7(1), 95-112. doi: 10.36510/learnland.v7i1.632

Chinta, S., Walker, K., Halliday, R., Loughran-Fowlds, A., \& Badawi, N. (2014). A comparison of the performance of healthy Australian 3-year-olds with the standardised norms of the Bayley Scales of Infant and Toddler Development (version-III). Archives of Disease in Childhood, 99(7), 621-624. doi: 10.1136/archdischild-2013-304834

Cohen, J. (1988). Statistical power analysis for the behavioral sciences (2nd ed.). Lawrence Erlbaum Associates.

Colombo, J., \& Cheatham, C. L. (2006). The emergence and basis of endogenous attention in infancy and early childhood. Advances in Child Development and Behavior, 34, 283-322. doi: 10.1016/ S0065-2407(06)80010-8

Colombo, J., \& Mitchel, D. W. (2009). Infant visual habituation. Neurobiology of Learning and Memory, 92(2), 225-234. doi: 10.1016/j.nlm.2008.06.002

Fuiko, R., Oberleitner-Leeb, C., Klebermass-Schrehof, K., Berger, A., Brandstetter, S., \& Giordano, V. (2019). The impact of norms on the outcome of children born very-preterm when using the Bayley-III: Differences between US and German norms. Neonatology, 116(1), 29-36. doi: $10.1159 / 000497138$

Greenspan, S. I., DeGangi, G., \& Wieder, S. (2001). The Functional Emotional Assessment Scale (FEAS): For infancy \& early childhood. Interdisciplinary Council on Development \& Learning Disorders.

Hanlon, C., Medhin, G., Worku, B., Tomlinson, M., Alem, A., Dewey, M., \& Prince, M. (2016). Adapting the Bayley Scales of Infant and Toddler Development in Ethiopia: Evaluation of reliability and validity. Child: Care, Health and Development, 42(5), 699-708. doi: 10.1111/cch.12371

Hegde, S., Rao, S. L., Raguram, A., \& Gangadhar, B. N. (2013). Cognitive remediation of neurocognitive deficits in schizophrenia. Neuropsychological Rehabilitation, 123-153. doi: 10.1016/b978-0-12-416046-0.00007-9

Hoskens, J., Klingels, K., \& Smits-Engelsman, B. (2018). Validity and cross-cultural differences of the Bayley Scales of Infant and Toddler Development, Third Edition in typically developing infants. Early Human Development, 125, 17-25. doi: 10.1016/j.earlhumdev.2018.07.002 
ПАВЛОВА П. А., БАКУШКИНА Н. И., СУЛЕЙМАНОвА Е. В., ПАВЛОВА Н. В., ЛАВРОВА М. А., ТУКТАРевА И. В., ... МАКСИМОВ Д. М. АПРОБАЦИЯ МЕТОДИКИ «Bayley Scales of Infant and Toddler Development - Third Edition»

Российский психологический жУРнАл, 2020, Т. 17, № 4, 49-64. doi: 10.21702/rpj.2020.4.4

ПСИХОЛОГИЯ РАЗВИТИЯ

Hua, J., Li, Y., Ye, K., Ma, Y., Lin, S., Gu, G., \& Du, W. (2019). The reliability and validity of Bayley-III cognitive scale in China's male and female children. Early Human Development, 129, 71-78. doi: 10.1016/j.earlhumdev.2019.01.017

Krogh, M. T., Væver, M. S., Harder, S., \& Køppe, S. (2012). Cultural differences in infant development during the first year: A study of Danish infants assessed by the Bayley-III and compared to the American norms. European Journal of Developmental Psychology, 9(6), 730-736. doi: 10.1080/17405629.2012.688101

Ranjitkar, S., Kvestad, I., Strand, T. A., Ulak, M., Shrestha, M., Chandyo, R. K., ... Hysing, M. (2018). Acceptability and reliability of the Bayley Scales of Infant and Toddler Development-III among children in Bhaktapur, Nepal. Frontiers in Psychology, 9, 1265. doi: 10.3389/fpsyg.2018.01265

Rao, U., Hammen, C. L., \& Poland, R. E. (2009). Ethnic differences in electroencephalographic sleep patterns in adolescents. Asian Journal of Psychiatry, 2(1), 17-24. doi: 10.1016/j.ajp.2008.12.003

Savostyanov, A. N., Bazovkina, D. V., Saprygin, A. N., Tamozhnikov, S. S., Ausheeva, T. A., Bocharov, A. V., ... Knyazev, G. G. (2018). The psychological and EEG effects of 5-HTTLPR gene polymorphism among people from different ethnic groups in Siberia. In Cognitive Sciences, Genomics and Bioinformatics (CSGB-2018): Symposium (p. 32). Novosibirsk: ICG SB RAS. doi: $10.18699 / \mathrm{csgb}-2018-26$

Steenis, L. J. P, Verhoeven, M., Hessen, D. J., \& van Baar, A. L. (2015). Performance of Dutch children on the Bayley III: A comparison study of US and Dutch norms. PLOS ONE, 10(8), e0132871. doi: 10.1371/journal.pone.0132871

Sun, L., Sabanathan, S., Thanh, P. N., Kim, A., Doa, T. T. M., Thwaites, C. L., ... Wills, B. (2019). Bayley III in Vietnamese children: Lessons for cross-cultural comparisons. Wellcome Open Research, 4, 98. doi: 10.12688/wellcomeopenres.15282.1

Weiss, L. G., Oakland, T., \& Aylward, G. P. (2010). Bayley-III clinical use and interpretation (1st ed.). Academic Press.

Yu, Y.-T., Hsieh, W.-S., Hsu, C.-H., Chen, L.-C., Lee, W.-T., Chiu, N.-C., ... Jeng, S.-F. (2013). A psychometric study of the Bayley Scales of Infant and Toddler Development - 3rd Edition for term and preterm Taiwanese infants. Research in Developmental Disabilities, 34(11), 3875-3883. doi: 10.1016/j.ridd.2013.07.006

Yue, A., Jiang, Q., Wang, B., Abbey, C., Medina, A., Shi, Y., \& Rozelle, S. (2019). Concurrent validity of the Ages and Stages Questionnaire and the Bayley Scales of Infant Development III in China. PLoS ONE, 14(9), e0221675. doi: 10.1371/journal.pone.0221675

Конфликт интересов отсутствует 